\author{
Marquette University \\ e-Publications@Marquette
}

3-1999

\title{
TGA/FTIR Studies on the Thermal Degradation of some Polymeric Sulfonic and Phosphonic Acids and Their Sodium Salts
}

\author{
David D. Jiang \\ Marquette University \\ Qiang Yao \\ Marquette University \\ Michael A. McKinney \\ Marquette University \\ Charles Wilkie \\ Marquette University, charles.wilkie@marquette.edu
}

Follow this and additional works at: https://epublications.marquette.edu/chem_fac

Part of the Chemistry Commons

\section{Recommended Citation}

Jiang, David D.; Yao, Qiang; McKinney, Michael A.; and Wilkie, Charles, "TGA/FTIR Studies on the Thermal Degradation of some Polymeric Sulfonic and Phosphonic Acids and Their Sodium Salts" (1999).

Chemistry Faculty Research and Publications. 758.

https://epublications.marquette.edu/chem_fac/758 


\section{Marquette University \\ e-Publications@Marquette}

\section{Chemistry Faculty Research and Publications/College of Arts and Sciences}

This paper is NOT THE PUBLISHED VERSION; but the author's final, peer-reviewed manuscript. The published version may be accessed by following the link in the citation below.

Polymer Degradation and Stability, Vol. 63, No. 3 (March, 1999): 423-434. DOI. This article is (C) Elsevier and permission has been granted for this version to appear in $\underline{\mathrm{e}}-$ Publications@Marquette. Elsevier does not grant permission for this article to be further copied/distributed or hosted elsewhere without the express permission from Elsevier.

\section{TGA/FTIR Studies on the Thermal Degradation of Some Polymeric Sulfonic and Phosphonic Acids and Their Sodium Salts}

David D. Jiang

Department of Chemistry, Marquette University, Milwaukee, WI

Q. Yao

Department of Chemistry, Marquette University, Milwaukee, WI

Michael A. McKinney

Department of Chemistry, Marquette University, Milwaukee, WI

Charles A. Wilkie

Department of Chemistry, Marquette University, Milwaukee, WI

\section{Abstract}

The thermal degradation of poly(vinyl sulfonic acid) and its sodium salt, poly(4-styrenesulfonic acid) and its sodium salt, and poly(vinylphosphonic acid) was studied by a combination of techniques, including TGA/FTIR, to identify the volatile products which were evolved during the 
degradation as well as analysis of the residues which were obtained in order to propose a mechanism for the degradation. The motivation for the work was to attempt to identify new monomers which could be graft copolymerized onto a polymer in order to improve the thermal stability of that polymer.

\section{Introduction}

The work of this laboratory has been involved for some time with understanding the thermal degradation processes which occur, in detail, so that one may use this information in order to develop flame retardants and flame retardant mechanisms. In particular we have developed processes in which char-forming monomers are graft copolymerized onto the surface of polymers in order to improve the thermal stability of the polymer. We have successfully graft copolymerized sodium methacrylate onto $\mathrm{ABS} \underline{1}, \underline{2}, \mathrm{SBS} \underline{\underline{3}}, \underline{4}, \underline{5}$ and acrylonitrile onto polystyrene $\underline{6}$, 7. It has become of interest to identify other polymers which may give a high yield of nonvolatile compounds upon thermolysis and this study was undertaken in order to examine such possibilities.

In this paper the thermal degradation of poly(vinylsulfonic acid) and its sodium salt, poly(vinylphosphonic acid), and poly(sodium 4-stryenesulfonic acid) are examined by a combination of techniques including thermogravimetric analysis, TGA, thermogravimetric analysis coupled to infrared spectroscopy, TGA/FTIR, and analysis of the residues which remain after evolution of volatiles in order to establish the mechanism by which the degradation occurs so that one can ascertain if it will be useful for thermal protection of polymers. Our interest in these polymers was stimulated by the observation that the samples show a very large volume expansion when the thermogravimetric analysis experiment is performed. Such an intumescent behavior suggests a possible flame retardant effect.

\section{Experimental}

The sodium salt of 4-styrenesulfonic acid and poly(sodium vinlysulfonate) were obtained from Aldrich Chemical Company while poly(vinylphosphonic acid) was purchased from Polysciences. Thermogravimetric analysis coupled to Fourier transform infrared spectroscopy, TGA/FTIR, was performed using a Cahn TG-131 thermogravimetric analyzer interfaced to a Mattson Galaxy infrared spectrometer under inert atmosphere or air at a scan rate of $20^{\circ} \mathrm{C}$ per minute. Thermogravimetric analysis was also performed using an Omnitherm 1000 unit under either a nitrogen or an air atmosphere at a scan rate of $20^{\circ} \mathrm{C}$ per minute. Infrared spectroscopy was performed using a Mattson Galaxy spectrometer while nuclear magnetic resonance spectra were obtained using a GE-300 instrument. Elemental analysis was done by Midwest Microlabs. All of the samples expanded in volume upon heating, the amount of volume expansion was noted by placing a quantity of the polymer in a melting point capillary or some other relatively small tube and heating the sample slowly in a sand bath to elevated temperatures. The samples were heated to temperatures between 200 and $500^{\circ} \mathrm{C}$ and the temperature was maintained for $30 \mathrm{~min}$ in order to ensure that the volume had completely expanded before a reading was taken. The height after volume expansion was compared to that of the unexpanded sample to give the volume expansion. 
The sodium salts of both poly(vinylsulfonic acid) and poly(4-styrenesulfonic acid) were converted to the free acid by flowing a dilute aqueous solution of the sodium salt through an ionic exchange column in the hydrogen form, Amberlite 120 (plus). The polymerization of sodium 4-styrenesulfonate was performed in aqueous solution using potassium persulfate as initiator at $60^{\circ} \mathrm{C}$ for $7 \mathrm{~h}$. After the polymerization was complete, the polymer was precipitated by the addition of acetone and methanol. The recovered polymer was redissolved in water and again precipitated; the precipitation-dissolution-precipitation was repeated three times and the material was assayed by NMR spectroscopy.

\section{Results and discussion}

\subsection{Poly(vinylsulfonic acid) sodium salt}

\subsubsection{Thermogravimetric analysis}

The TGA curves of the sodium salt of poly(vinylsulfonic acid) under both $\mathrm{N}_{2}$ and air are shown in Fig. 1. Three stages of degradation are evident in these curves, the first begins at about $200^{\circ} \mathrm{C}$ and continues to $350^{\circ} \mathrm{C}$, the second stage is from 350 to $400^{\circ} \mathrm{C}$, while the last stage commences at 400 and ends at $570^{\circ} \mathrm{C}$. Approximately $5 \%$ of the mass is lost before $350^{\circ} \mathrm{C}$ while $55 \%$ is not volatile at $600^{\circ} \mathrm{C}$ and this is still not volatilized at $1000^{\circ} \mathrm{C}$. An identical result is obtained when the thermogravimetric analysis is performed in air. One ordinarily does not expect that the TGA curves will be the same in air and in an inert atmosphere and this most likely indicates that an inorganic residue is produced since an organic residue should burn. The production of foam is noted when the sample is heated either in nitrogen or in air. The formation of foam is first observed at $370^{\circ} \mathrm{C}$ and the volume expansion is at least five times and it appears to be dependent upon the heating rate and the temperature. An inorganic residue would not be expected to foam so the TGA result suggest the formation of an inorganic reside while the foaming says that it must also have an organic component at the temperature at which the volume expansion occurs.

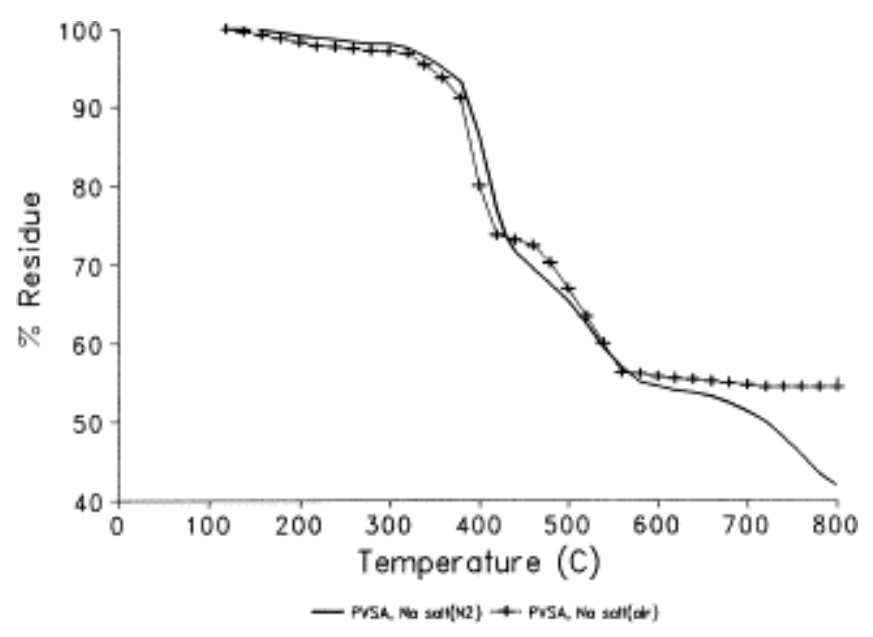

Fig. 1. Thermogrvimetric analysis of (sodium vinylsulfonate) at $20^{\circ} \mathrm{C} /$ minute under nitrogen and air. 


\subsubsection{Volatile products evolved during the degradation}

In the first stage of the degradation of poly(sodium vinylsulfonate), below $300^{\circ} \mathrm{C}$, the only product which is observed is water. The salt is very soluble in water and it is also hygroscopic; the formation of water at this stage is probably simply due to the release of physically bound water. More products are observed at higher temperatures and these include water (3854 $\left.\mathrm{cm}^{-1}\right)$, sulfur dioxide $\left(1360 \mathrm{~cm}^{-1}\right)$, ethylene $\left(949 \mathrm{~cm}^{-1}\right)$, carbon disulfide $\left(1540 \mathrm{~cm}^{-1}\right)$, carbonyl sulfide $\left(2070 \mathrm{~cm}^{-1}\right)$, and carbon monoxide $\left(\mathrm{CO}, 2182 \mathrm{~cm}^{-1}\right)$. Infrared assignments were based upon observed spectra from the Aldrich library ${ }^{[8]}$ and a compendium of gas phase infrared spectra[9]. In air the evolution of water (Fig. 2) begins near $320^{\circ} \mathrm{C}$, reaches a maximum at $400^{\circ} \mathrm{C}$ and is complete at $550^{\circ} \mathrm{C}$; in nitrogen the onset temperature and the temperature of maximum absorbance are unchanged but a very small amount continues to evolve to the highest temperature used in this study. The evolution of $\mathrm{SO}_{2}$ (Fig. 3) also commences at $300^{\circ} \mathrm{C}$ and maximizes at $400^{\circ} \mathrm{C}$ and begins to decrease and then another increase begins; the evolution continues at a low level until $750^{\circ} \mathrm{C}$ in air. Much more $\mathrm{SO}_{2}$ is observed in air than in nitrogen. The evolution of ethylene (Fig. 4) begins at $360^{\circ} \mathrm{C}$, a temperature at which significant amounts of water and $\mathrm{SO}_{2}$ are being evolved, and is complete by $450^{\circ} \mathrm{C}$; this is a narrow temperature region compared to the other products. The evolution of $\mathrm{CS}_{2}$ begins at about $300^{\circ} \mathrm{C}$ and reaches a maximum at $400^{\circ} \mathrm{C}$ and has ended by $500^{\circ} \mathrm{C}$. There is a peak in the spectrum of the evolved gases at $3068 \mathrm{~cm}^{-1}$ which may be due to the $\mathrm{C}-\mathrm{H}$ stretching frequency of an aromatic compound. This begins at about $350^{\circ} \mathrm{C}$ and reaches a maximum at $400^{\circ} \mathrm{C}$ and is finished by $460^{\circ} \mathrm{C}$. Two other compounds are observed, $\mathrm{CO}$ and $\mathrm{COS}$, and these patterns are different in air than in nitrogen. In air the evolution of $\mathrm{CO}$ begins at $320^{\circ} \mathrm{C}$ and reaches a maximum at $500^{\circ} \mathrm{C}$ and ends at $700^{\circ} \mathrm{C}$; in nitrogen very little $\mathrm{CO}$ is evolved, it begins at about $500^{\circ} \mathrm{C}$ and continues throughout the course of the degradation. Likewise for COS very little is formed in inert atmosphere, the little which is formed begins at about $400^{\circ} \mathrm{C}$ and continues until $750^{\circ} \mathrm{C}$. In air the evolution of COS begins at $380^{\circ} \mathrm{C}$ and reaches a maximum at $500^{\circ} \mathrm{C}$ and ends by $600^{\circ} \mathrm{C}$.

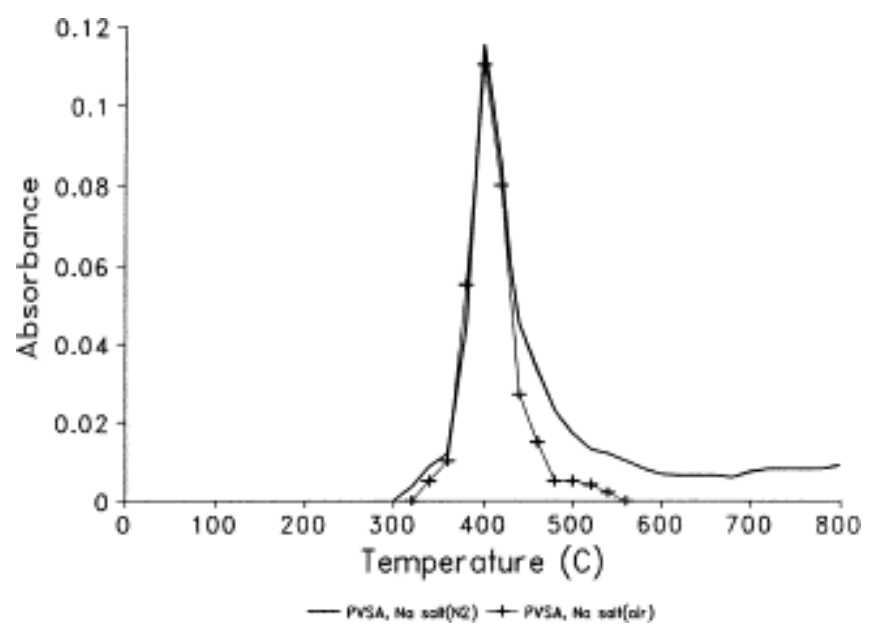

Fig. 2. Absorbance of evolved water from the degradation of poly(sodium vinylsulfonate) as a function of temperature under both nitrogen and air. 


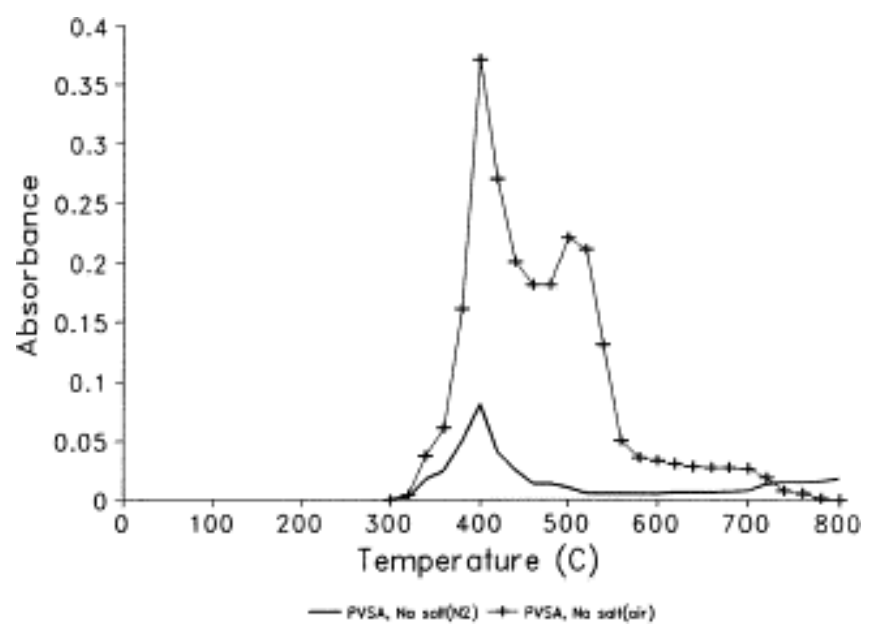

Fig. 3. Absorbance of evolved sulfur dioxide from the degradation of poly(sodium vinylsulfonate) under both nitrogen and air.

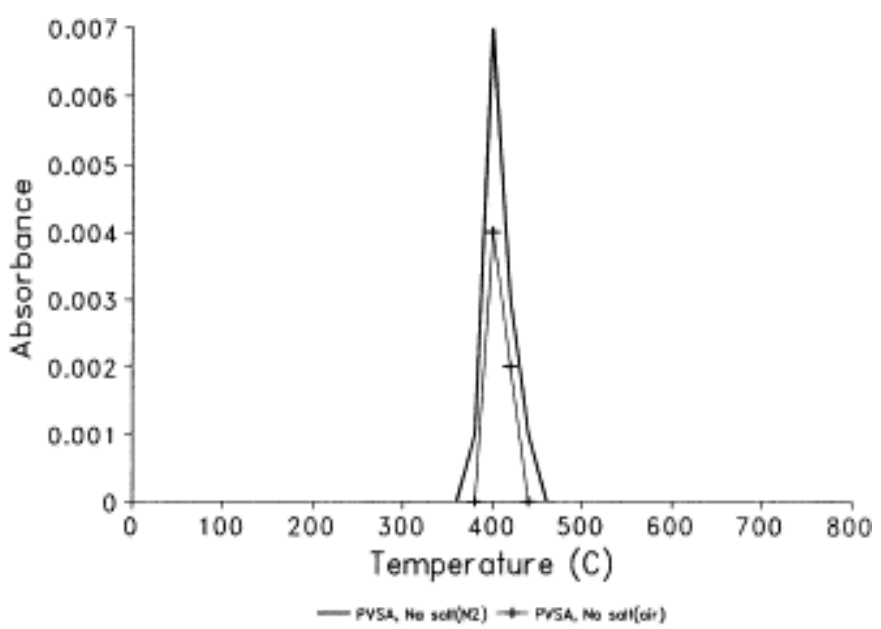

Fig. 4. Absorbance of ethylene from the thermal degradaton of poly(sodium vinylsulfonate) under both nitrogen and air.

\subsubsection{Analysis of residues}

The residues obtained at different temperatures under inert atmosphere were characterized by elemental analysis, solubility, infrared and nuclear magnetic resonance spectroscopy. The virgin polymer contains $18.46 \%$ carbon, $2.31 \%$ hydrogen, and $24.62 \%$ sulfur; the residue which has been recovered after heating the polymer to $1000^{\circ} \mathrm{C}$ under nitrogen contains $1.86 \%$ carbon, $0 \%$ hydrogen, and $16.96 \%$ sulfur. This residue recovered after heating to $1000^{\circ} \mathrm{C}$ is largely non-volatile and gives $97.4 \%$ ash.

The solubility tests show that the residues below $400^{\circ} \mathrm{C}$ are soluble in water; at $420^{\circ} \mathrm{C}$ the residue is only partially soluble and above $450^{\circ} \mathrm{C}$, it is insoluble. The color changes from light to dark as the temperature increases. All residues obtained between 300 and $800^{\circ} \mathrm{C}$ were characterized by infrared spectroscopy. Below $350^{\circ} \mathrm{C}$ the IR spectrum is identical to that of virgin polymer. Between 380 and $400^{\circ} \mathrm{C}$, new strong bands appear at 1003 and $1130 \mathrm{~cm}^{-1}$, the 
band at $1130 \mathrm{~cm}^{-1}$ is characteristic of the sulfate ion ${ }^{[10]}$ while the band at $1003 \mathrm{~cm}^{-1}$ is characteristic of the sulfite ion ${ }^{[11]}$. The IR spectra of samples obtained above $450^{\circ} \mathrm{C}$ are similar and are characterized by the diminution of the band at $1003 \mathrm{~cm}^{-1}$ and the appearance of a new band at $967 \mathrm{~cm}^{-1}$. The sulfite ion shows two bands in this region and the band at $967 \mathrm{~cm}^{-1}$ corresponds to the second band and this confirms the assignment. When the residue is washed with water, the bands at 1130 and $967 \mathrm{~cm}^{-1}$ appear in the spectra of the water soluble compound and this further confirms the presence of both sulfate and sulfite in the residue.

The samples obtained below $400^{\circ} \mathrm{C}$ are water soluble and were characterized by ${ }^{1} \mathrm{H}$ NMR spectroscopy. Below $300^{\circ} \mathrm{C}$ the spectrum matches with that of virgin polymer and this indicates no thermal degradation below $300^{\circ} \mathrm{C}$. When the spectrum of a residue obtained by heating to $\mathrm{a}$ temperature between 380 and $400^{\circ} \mathrm{C}$ is examined, a new band appears at $7.3 \mathrm{ppm}$ which is in the aromatic region and which also agrees with the observation of an aromatic $\mathrm{C}-\mathrm{H}$ stretching vibration in the infrared spectrum of the volatiles.

\subsubsection{Mechanism of degradation}

In this section we shall only attempt to propose a mechanism for the degradation of poly(sodium vinylsulfonate) conducted under an inert atmosphere; the presence of oxygen in the reaction does not appear to have a great affect on the course of the reaction based upon the appearance of volatile products and the TGA curve but is nonetheless beyond the scope of our investigation. The available data show that both sulfite ion and sulfate ion are found in the non-volatile residue along with a small amount of carbon which is likely in some form of graphite based upon the observation of aromatic compounds in both the volatiles and residue. The observation of foaming requires that some carbon compound be present since the inorganic will not foam. The first volatile products to appear are water and sulfur dioxide and this begin to evolve at $300^{\circ} \mathrm{C}$. Carbon disulfide is also produced at this same temperature while the evolution of both ethylene and aromatics begins at $360^{\circ} \mathrm{C}$.

The first step of the degradation involves the cleavage of the carbon sulfur bond to give a carbon-based radical along the polymer chain and an $\mathrm{SO}_{3} \mathrm{Na}$ radical. This sulfur-based radical can now react in two different ways. The reaction which explains the formation of $\mathrm{SO}_{2}, \mathrm{H}_{2} \mathrm{O}$, and sulfite ion involves reaction of the $\mathrm{SO}_{3} \mathrm{Na}$ radical as an oxygen-based radical with the polymer chain to remove a hydrogen atom with the formation of sodium hydrogen sulfite. Sodium hydrogen sulfite disproportionates to give sodium sulfite and sulfur dioxide and water. The formation of $\mathrm{CS}_{2}$ and $\mathrm{COS}$ must occur through some other, and as yet unidentified, reaction of the sulfur-based radical with some carbon species.

The second pathway is displacement on sulfur by the $\mathrm{SO}_{3} \mathrm{Na}$ radical to give eventually sodium sulfate and sulfur dioxide. These two pathways occur in different temperature regimes as is shown by the profile of $\mathrm{SO}_{2}$ evolution in Fig. 3 . The low temperature pathway produces sulfite while at higher temperatures sulfate is formed. The formation of inorganic products by these degradation pathways is shown in Scheme. 1. 

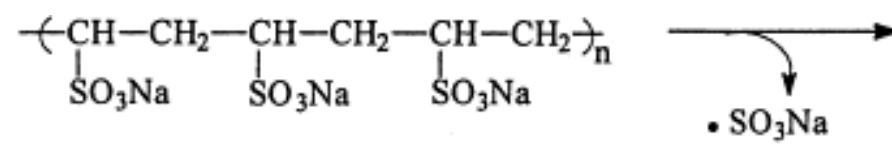

$\underset{\mathrm{SO}_{3} \mathrm{Na}}{\left.+\mathrm{CH}-\mathrm{CH}_{2}-\mathrm{CH}-\mathrm{CH}_{2}-\underset{\mathrm{CH}}{\mathrm{C}}-\mathrm{CH}_{2}\right)_{\mathrm{n}}} \underset{\mathrm{SO}_{3} \mathrm{Na}}{ }$

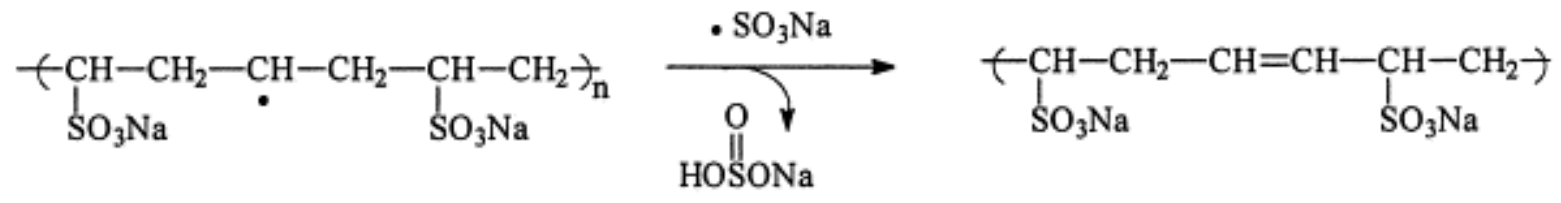

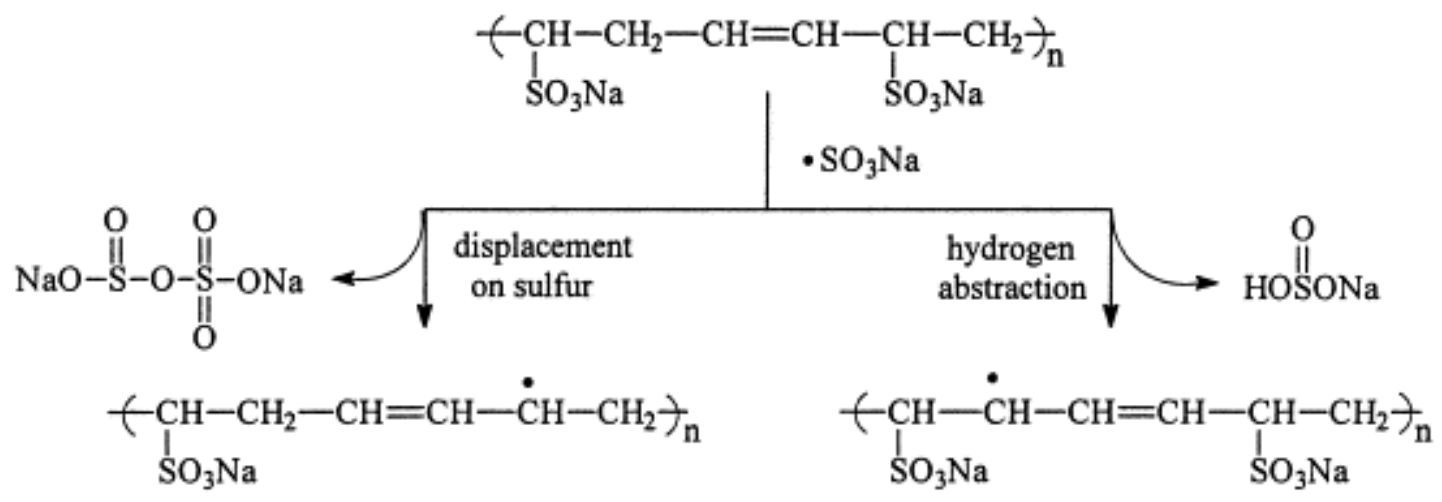

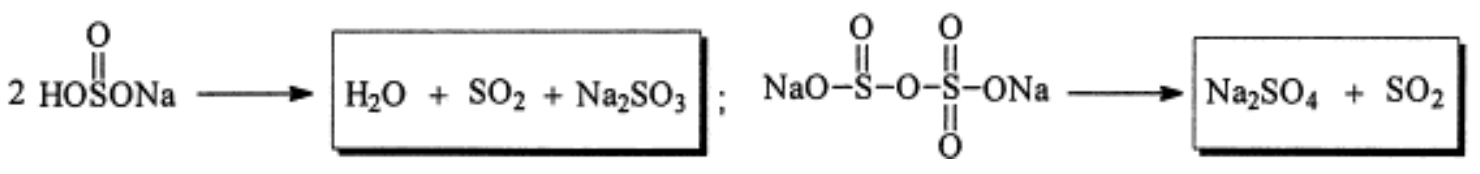

Scheme. 1.

The fate of the carbon-based radical is depicted in Scheme. 2. Here the $\mathrm{SO}_{3} \mathrm{Na}$ radical hydrogen abstracts from the polymer chain with the formation of a polyacetylene. It has previously been reported that polyacetylene will form aromatic chars ${ }^{[12]}$. Finally the carbonbased radicals can also undergo fragmentation, a route which leads to the formation of ethylene as shown in Scheme. 3. 

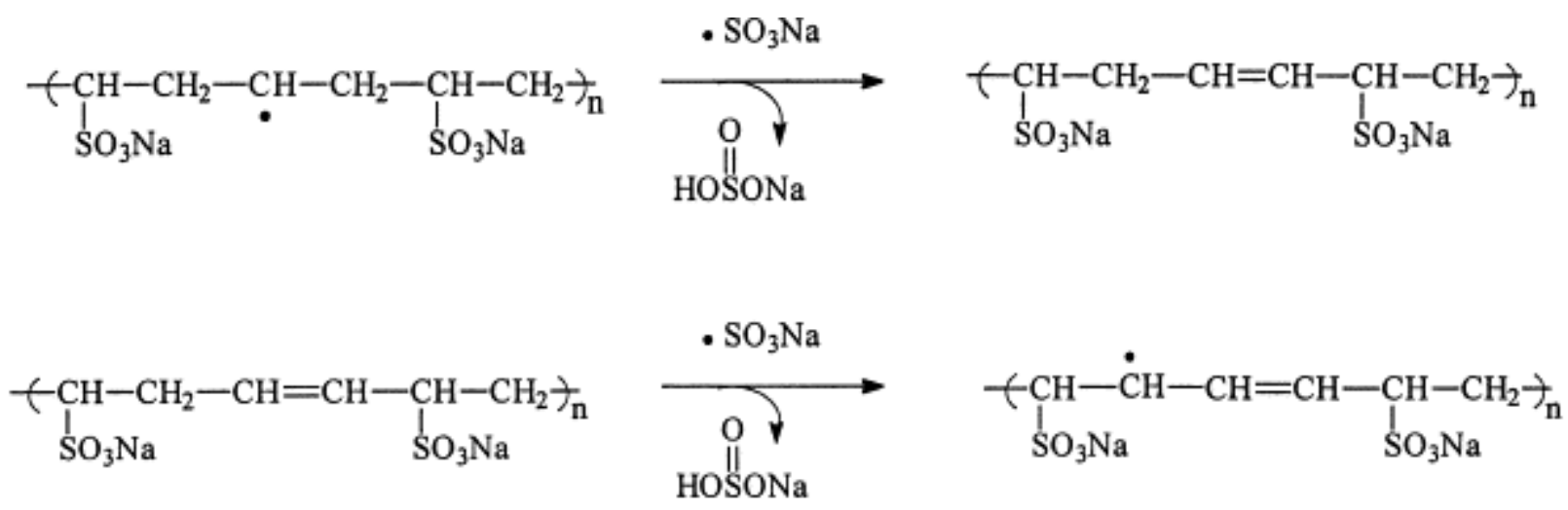<smiles>CCC(C=CC(C)[S+]([O])(=O)[O-])[Si](=O)(=O)[O-]</smiles>

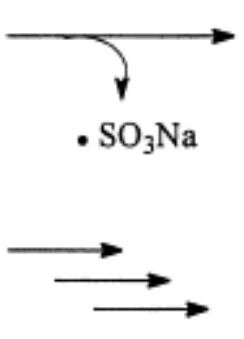<smiles>CC=CC=CC(CC)[S+](=O)[O-]</smiles><smiles>CC=CC=CC(CC)[S+](=O)[O-]</smiles><smiles>CC=CC=CC=CC</smiles>

Scheme. 2.

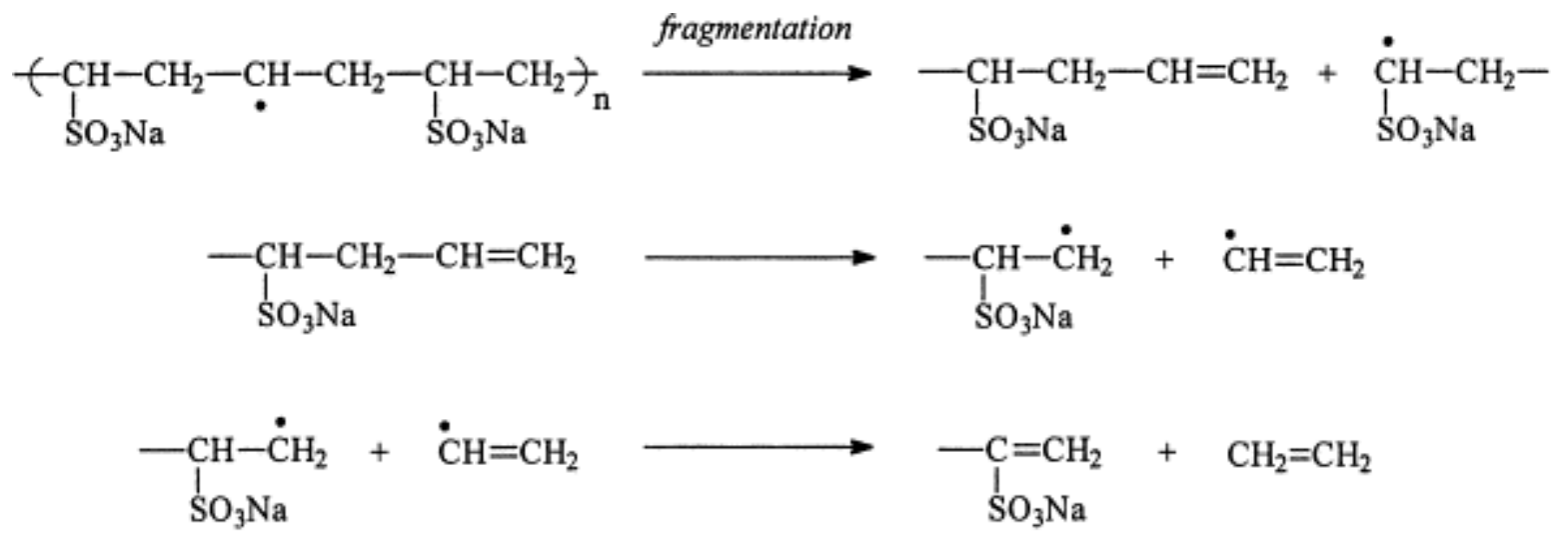

Scheme. 3.

\subsection{Poly(vinylsulfonic acid)}

\subsubsection{Thermogravimetric analysis}

The TGA curves for poly(vinylsulfonic acid) under both nitrogen and air are shown in Fig. 5. Poly(vinylsulfonic acid) degrades much earlier and shows a much lower non-volatile residue than its sodium salt. The degradation occurs in four stages; the initial stage, 70 to $150^{\circ} \mathrm{C}$, is most likely the result of physically retained water in the sample. The actual degradation commences at $150^{\circ} \mathrm{C}$ and this stage continues to a little less than $300^{\circ} \mathrm{C}$. The third stage 
involves only a little degradation and occurs over the temperature range of 300 to $500^{\circ} \mathrm{C} ; 20 \%$ of the sample is non-volatile at $600^{\circ} \mathrm{C}$ while $5 \%$ mass loss occurs at $125^{\circ} \mathrm{C}$. The degradation of the acid produces a large amount of foaming. The volume of the sample expands by a factor of 15 and the formation of foam begins at about $170^{\circ} \mathrm{C}$. Like its sodium salt, the TGA curve is virtually identical in both air and nitrogen.

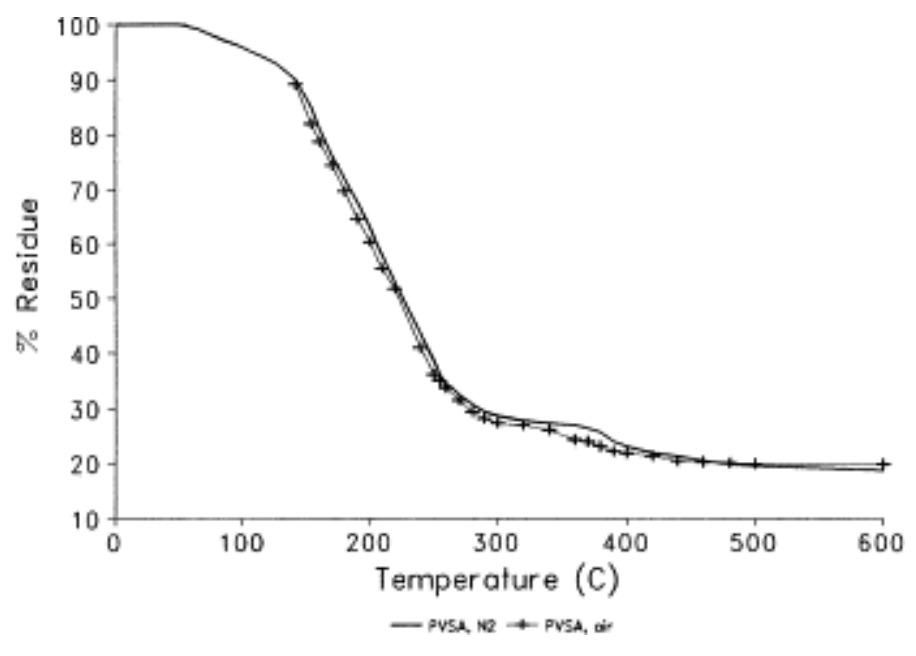

Fig. 5. Thermogravimetric analysis of poly(vinylsulfonic acid) at $20^{\circ} \mathrm{C} /$ minute under both nitrogen and air.

\subsubsection{Volatile products evolved during the degradation}

The volatile products evolved from poly(vinylsulfonic acid) include water, sulfur dioxide, and ethylene. Three other compounds, carbon disulfide, carbonyl sulfide, and carbon monoxide, are also observed but the former two are only observed in air and one more volatile product, methane $\left(\mathrm{CH}_{4}, 3018 \mathrm{~cm}^{-1}\right)$, is only observed in nitrogen. The only gas evolved in the earliest stage of degradation, 70 to $150^{\circ} \mathrm{C}$, is water and this agrees with the suggestion that this is due only to the loss of physically retained water from the acid. The temperatures at which the volatile products appear is earlier for free acid than for the sodium salt. The evolution of water and $\mathrm{SO}_{2}$ begins at 120 and $150^{\circ} \mathrm{C}$, respectively, for free acid but at $320^{\circ} \mathrm{C}$ for the sodium salt and ethylene appears at $200^{\circ} \mathrm{C}$ for free acid but above $350^{\circ} \mathrm{C}$ for the sodium salt. The other volatile products, $\mathrm{CS}_{2}, \mathrm{COS}$, and $\mathrm{CO}$, appear at the same temperature as for the sodium salt.

The evolution of ethylene (Fig. 6) and water (Fig. 7) show two peaks for free acid; by matching these figures with those from the sodium salt one can see that the second stage of ethylene and water evolution corresponds to that of the sodium salt. The absorbance of $\mathrm{SO}_{2}$ versus temperature (Fig. 8) is very broad and covers the range of 160 to $400^{\circ} \mathrm{C}$ so it is not possible to see if there is such correspondance between the evolution of $\mathrm{SO}_{2}$ from the salt and the second stage of acid degradation. The free acid is obtained by passing the polymeric sodium salt through an ion exchange column in the acid form; the conversion to the acid form is incomplete and some of the salt will remain. The early degradation is assigned as that due to the acid form while the later steps are due to the degradation of the salt. In the case of ethylene, water, and 
sulfur dioxide, one can see that the degradation of the acid produces the same components as does the degradation of the sodium salt.

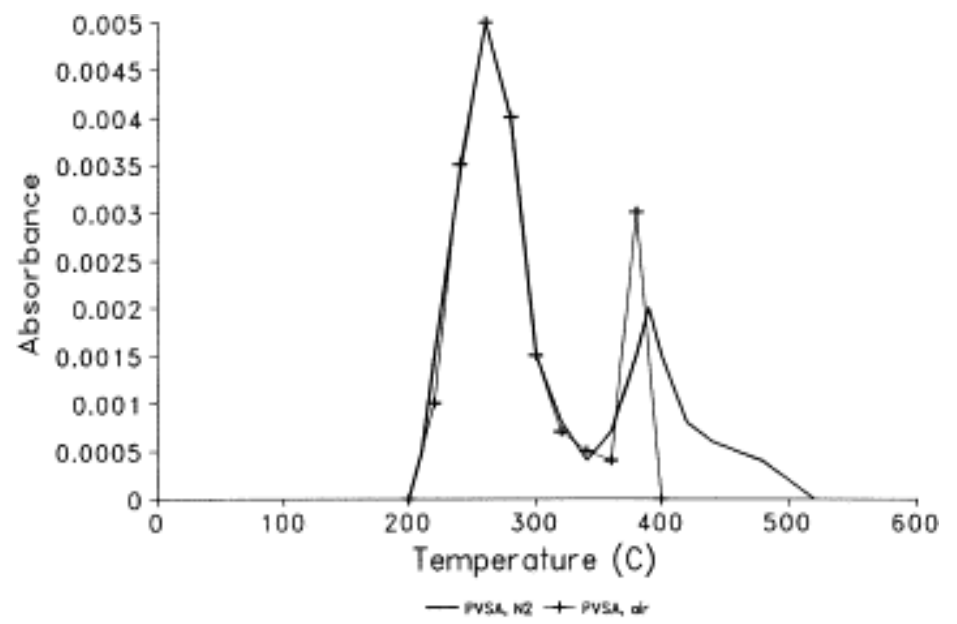

Fig. 6. Evolution of ethylene from the thermal degradation of poly- (vinylsulfonic acid) under both nitrogen and air.

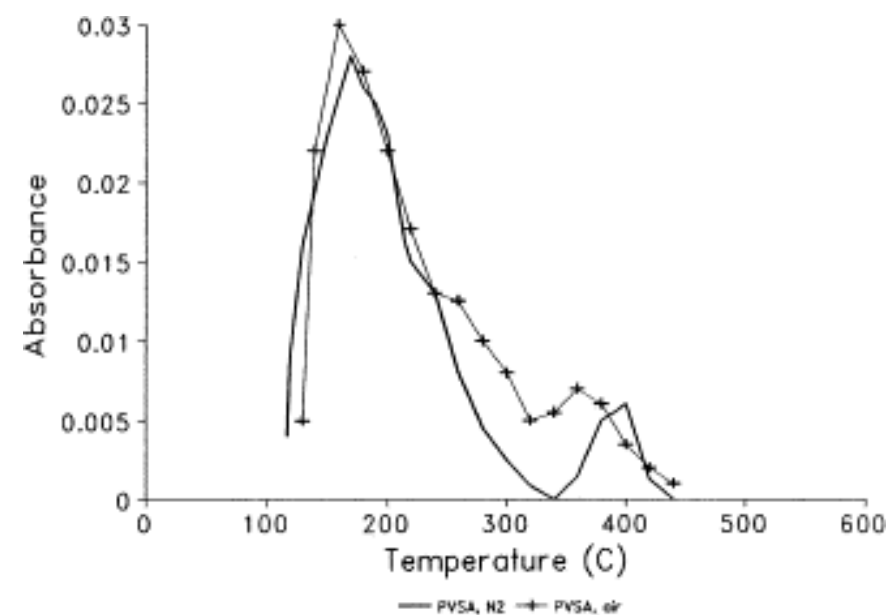

Fig. 7. Evolutin of water from the thermal degradation of poly- (vinylsulfonic acid) under both nitrogen and air. 


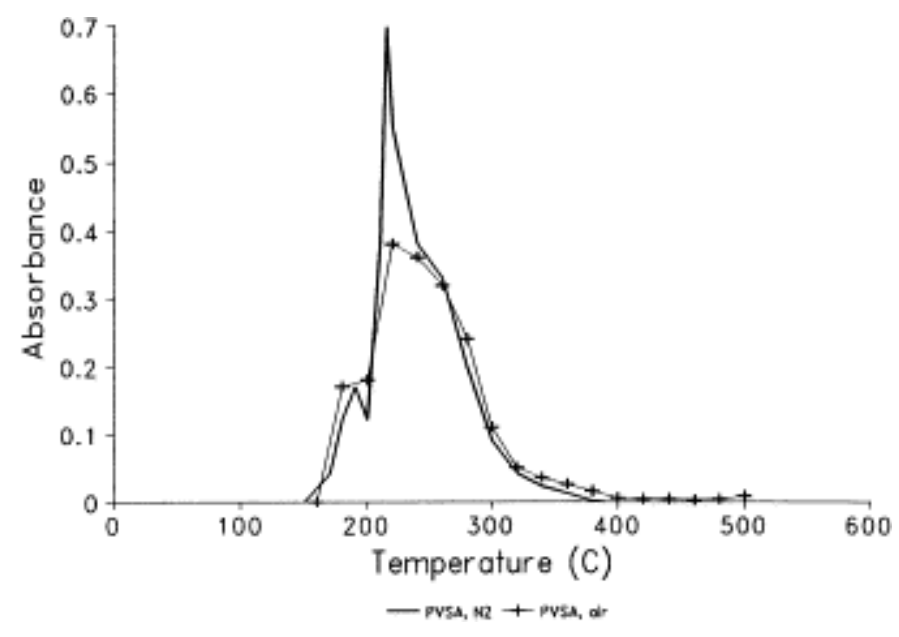

Fig. 8. Evolution of sulfur dioxide from the thermal degradation of poly(vinylsulfonic acid) under both nitrogen and air.

The observation that methane is evolved beginning at $350^{\circ} \mathrm{C}$ and reaching a maximum at $520^{\circ} \mathrm{C}$ in nitrogen is of great interest. This evolution occurs during the stage which is identified with the degradation of the sodium salt and not the degradation of the free acid. In the degradation of the sodium salt discussed above, several products were observed which contain only one carbon atom and it was speculated that these materials may arise from secondary reactions involving a one carbon species with some sulfur-based free radical. In the degradation of the sodium salt, methane was not observed but here it is observed during the degradation of what is assumed to be residual sodium salt. This increases the likelihood of the speculation on the nature of the secondary reaction products.

The evolution of $\mathrm{SO}_{2}$ from the free acid ends significantly earlier than it does in the sodium salt yet the acid contains some amount of the sodium salt. The volume expansion which occurs with the free acid is much larger than that of the sodium salt and this may form a protective layer to prevent the further degradation of the salt.

\subsubsection{Analysis of residues}

The polymeric acid should contain $22.22 \%$ carbon, $3.70 \%$ hydrogen, and $29.63 \%$ sulfur; elemental analysis of the residue obtained by heating the sample to $600^{\circ} \mathrm{C}$ in a nitrogen atmosphere indicates that this residue contains $59.81 \%$ carbon, $1.45 \%$ hydrogen, and $8.28 \%$ sulfur and $26.3 \%$ of the sample is ash or inorganic. The amount of carbon in the residue is much larger and that of hydrogen significantly lower than that of the starting material and gives credence to the idea that aromatization of the sample occurs. Infrared analysis of the residue shows a band at $1130 \mathrm{~cm}^{-1}$ which is assignable to sulfate ion and confirms the presence of some amount of sodium salt in the acid sample.

The residue which is obtained when the sample is heated to a temperature below $230^{\circ} \mathrm{C}$ is soluble in water and above $300^{\circ} \mathrm{C}$ the samples are completely insoluble. At intermediate temperatures, the sample is partially soluble. 


\subsubsection{Mechanism of degradation}

The only differences between the degradation of the acid and its sodium salt are the temperatures at which the various gaseous products appear, the amount of non-volatile residue, and the volume expansion which occurs upon heating. The overall mechanism of the degradation of the acid should be virtually identical with that of the sodium salt except for the absence of sulfite ion. In the degradation of the salt, sulfite arises when sodium hydrogen sulfite disproportionates. In this case, sulfurous acid will form by hydrogen abstraction from the polymer by the $\mathrm{SO}_{3} \mathrm{H}$ radical; this will directly give $\mathrm{SO}_{2}$ and $\mathrm{H}_{2} \mathrm{O}$ and there is no need for disproportionation. The non-volatile residue which is formed is due to the fraction of sodium salt which remains after ion exchange. The volume expansion may be due to the greater amount of gas which evolves and/or the greater fraction of carbon which the residue contains.

\subsection{Poly(vinylphosphonic acid)}

\subsubsection{Thermogravimetric analysis}

The TGA curves for poly(vinyl phosphonic acid) in both air and nitrogen are shown in Fig. 9. Once again the curves are quite similar in the two atmospheres but there is slightly less nonvolatile residue in air than in nitrogen. In nitrogen one can see three steps of degradations with only two in air. The initial mass loss begins at about $200^{\circ} \mathrm{C}$ and this first step ends at about $470^{\circ} \mathrm{C}$, about $15 \%$ of the mass is lost in this stage. The second stage accounts for the loss of $20 \%$ of the mass and occurs between 470 and $510^{\circ} \mathrm{C}$. The third, slower stage of mass loss, begins at $510^{\circ} \mathrm{C}$ and continues to $680^{\circ} \mathrm{C}$ and this accounts for $25 \%$ of the mass. At $800^{\circ} \mathrm{C}$ the non-volatile residue in nitrogen is $40 \%$. When the degradation is conducted in air, the initial step of degradation begins at $200^{\circ} \mathrm{C}$ and ends at $500^{\circ} \mathrm{C}$ and it accounts for $10 \%$ of the mass loss. The second step of degradation accounts for $60 \%$ of the mass loss and occurs over the range of 500 to $700^{\circ} \mathrm{C}$. The non-volatile residue at $800^{\circ} \mathrm{C}$ is $20 \%$. Foaming also occurs with this compound and a volume expansion of 10 times is seen at $430^{\circ} \mathrm{C}$.

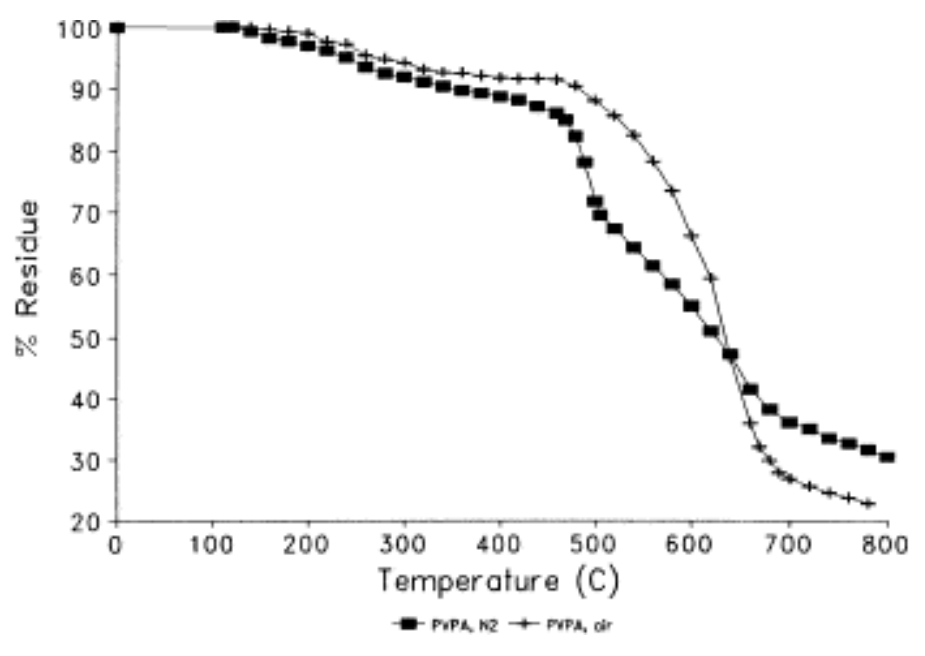

Fig. 9. Thermogravimetric analysis of poly(vinylphosphonic acid) at $20^{\circ} \mathrm{C} / \mathrm{min}$ under both nitrogen and air. 


\subsubsection{Volatile products evolved during the degradation}

The gases evolved from poly(vinyl phosphonic acid) include water, olefins including ethylene, propene $\left(991 \mathrm{~cm}^{-1}\right)$, butene $\left(912 \mathrm{~cm}^{-1}\right)$ and butadiene $\left(889 \mathrm{~cm}^{-1}\right)$, methane, phosphines including $\mathrm{PH}_{3}\left(2403 \mathrm{~cm}^{-1}\right)$, and $\mathrm{R} 2 \mathrm{PH}$ or $\mathrm{RPH}_{2}\left(2326\right.$ and $\left.2321 \mathrm{~cm}^{-1}\right)$, and carbon monoxide; the phosphines are only observed in an inert atmosphere.

The evolution of the two major products, water and ethylene, are shown in Fig. 10 and Fig. 11. The evolution of water occurs in two steps with a minor amount evolving between 100 and $320^{\circ} \mathrm{C}$ and the major amount between 400 and $600^{\circ} \mathrm{C}$. The early evolution of water is likely due to release of physically bound water but the fact that this continues to higher temperature suggests that some of the water evolution is due to polymer degradation. Ethylene also evolves in two steps but they are of about equal magnitude; the first stage of ethylene evolution occurs between 200 and $400^{\circ} \mathrm{C}$ while the second stage is 400 to $550^{\circ} \mathrm{C}$. The first evolution of ethylene is due to the decomposition of monomer which is present in the polymer; the presence of monomer has been shown by NMR spectroscopy. The evolution of the other olefins and butadiene coincides with the second stage of ethylene. Phosphines are observed between 420 and $520^{\circ} \mathrm{C}$ while methane appears at $390^{\circ} \mathrm{C}$ and ends at $570^{\circ} \mathrm{C}$ and $\mathrm{CO}$ evolution begins around $480^{\circ} \mathrm{C}$.

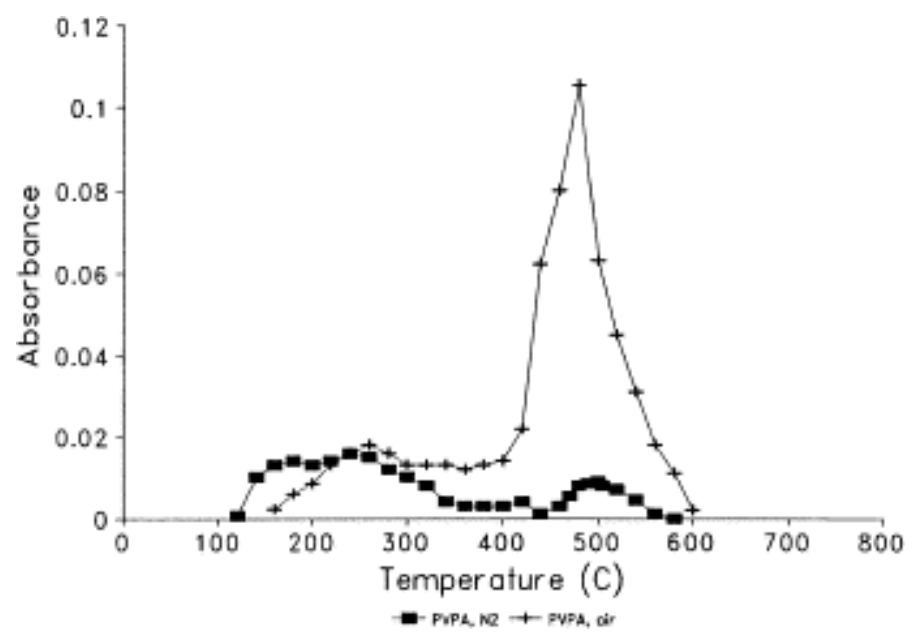

Fig. 10. Absorbance of water from the thermal degradation of poly(vinylphosphonic acid) under nitrogen and air. 


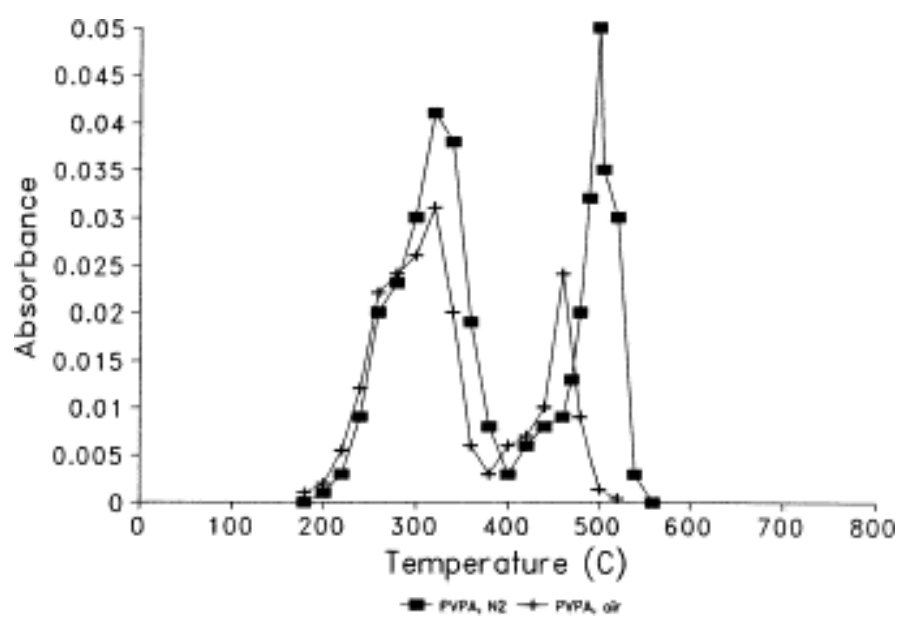

Fig. 11. Absorbance of ethylene from the thermal degradation of poly(vinylphosphonic acid) under both nitrogen and air.

\subsubsection{Analysis of residues}

The virgin polymer contains $22.43 \%$ carbon and $3.74 \%$ hydrogen; a sample recovered after pyrolysis at $1000^{\circ} \mathrm{C}$ contains $37.84 \%$ carbon and $0.81 \%$ hydrogen. Unfortunately there was not enough material to obtain a phosphorus analysis. The large amount of carbon and small amount of hydrogen in the residue suggests again that graphitization of the sample is occurring. The virgin polymer is quite soluble in water at room temperature. When the sample is heated to $300^{\circ} \mathrm{C}$ in nitrogen, it will dissolve within 5 minutes while a sample heated to $400^{\circ} \mathrm{C}$ dissolves in $30 \mathrm{~min}$. The NMR spectrum of each of these samples is identical with that of virgin polymer. When the sample is heated to $500^{\circ} \mathrm{C}$ or higher, it becomes insoluble. The increase in time required to dissolve the sample suggests that there is some change in structure while the NMR data argues that the material after dissolution is the same. It is possible that water may be lost with the formation of $\mathrm{P}-\mathrm{O}-\mathrm{P}$ linkages. This will hydrolyze in water to reform the acid.

The infrared spectrum of the residue obtained by heating at $500^{\circ} \mathrm{C}$ shows a band at $1314 \mathrm{~cm}^{-1}$ which may be assigned to a P $\square$ O vibration. This, together with the elemental analysis, indicates the presence of phosphorus in the residue, probably as some phosphorus oxide.

\subsubsection{Mechanism of the degradation}

The initial step in the degradation is the formation of anhydrides based upon the solubility data. This is depicted in Scheme. 4. These anhydrides may form either intra- or inter-molecularly and will form and break and have little difference on the overall reaction pathway. In subsequent steps the acid is depicted since it should make little difference which material is present. 


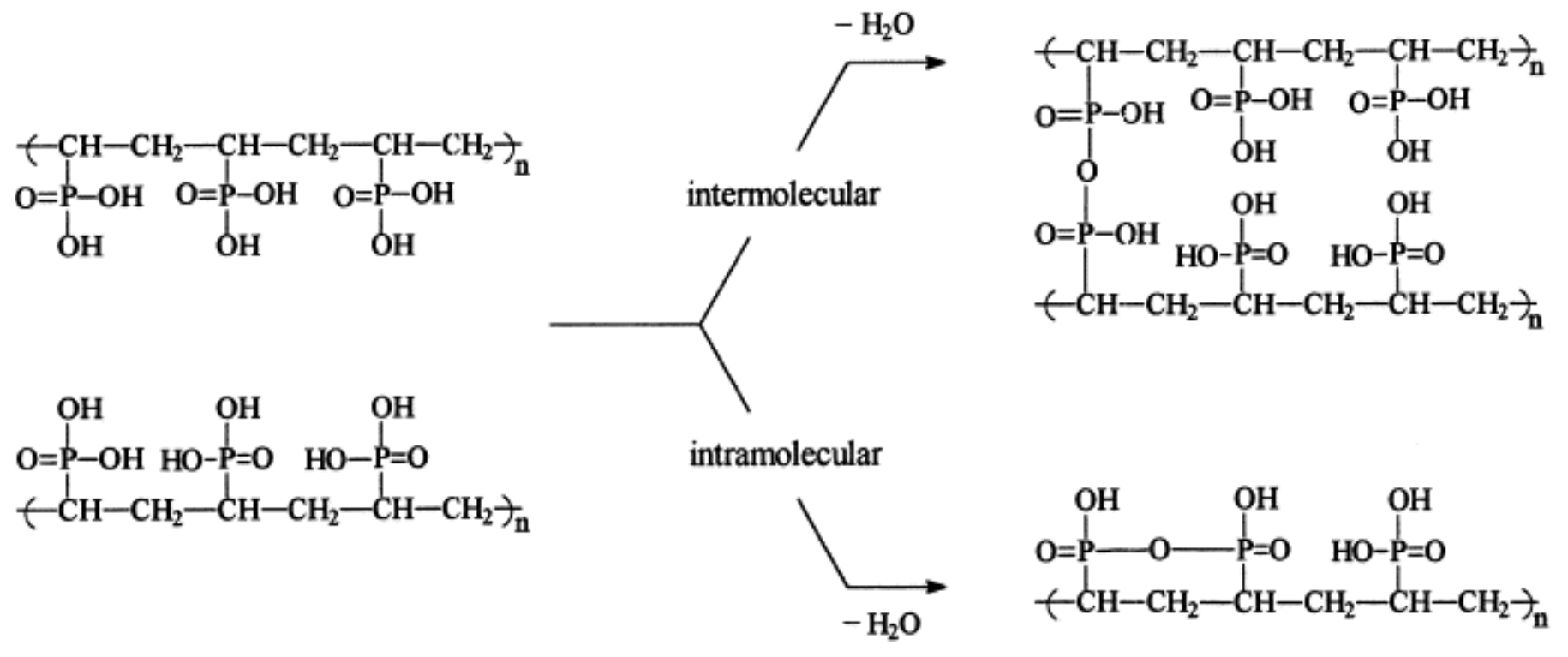

Scheme. 4.

The overall degradation pathway is remarkably similar to that observed above. The cleavage of the carbon-phosphorus bond gives a $\mathrm{PO}_{3} \mathrm{H}_{2}$ radical which by hydrogen abstraction leads to the formation of phosphorous acid. This can dehydrate to the oxide, $\mathrm{P}_{2} \mathrm{O}_{3}$, and water and this accounts for the products which have been observed.

The carbon-based radical will now degrade as seen for vinylsulfonic acid to give polyacetylene and eventually the graphitic char. Ethylene will be formed as noted for the sulfur compound. Two new olefins are observed in this degradation, butene and butadiene. The formation of these olefins is depicted in Scheme. 5 and Scheme. 6 , respectively. The reason these are observed in the phosphorus- but not in the sulfur-containing polymer is due to the presence of phosphorus acid. This is a good hydrogen atom donor and enables their formation. 


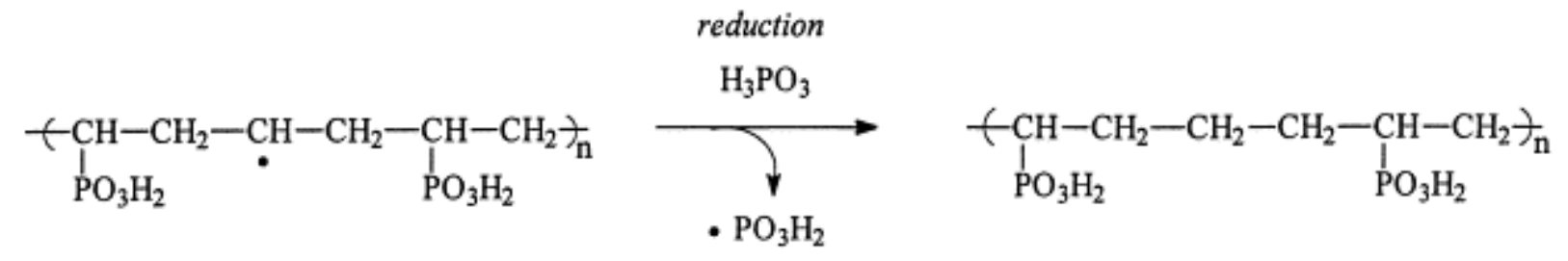

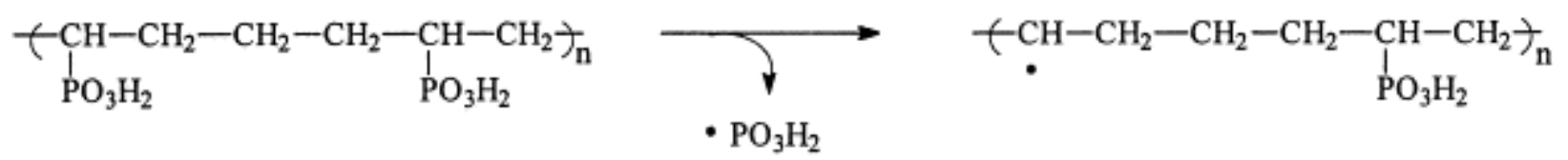

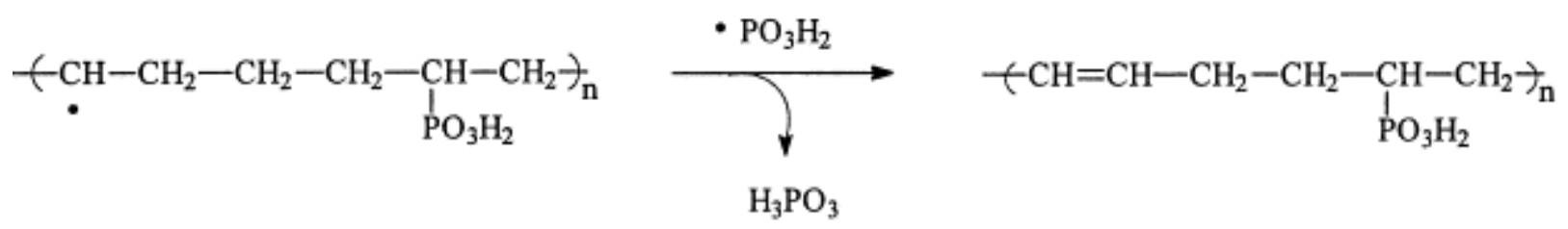

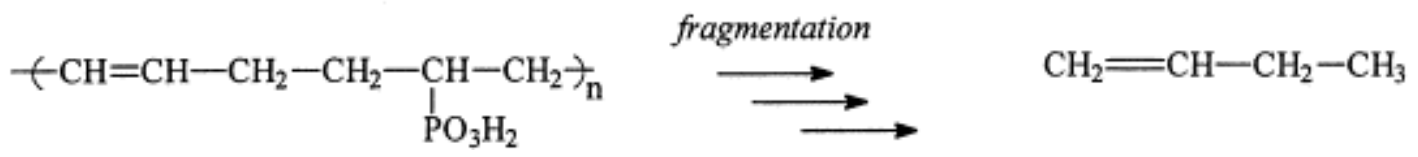

Scheme. 5.

$$
\begin{aligned}
& \underset{\substack{l \\
\mathrm{PO}_{3} \mathrm{H}_{2}}}{\mathrm{CH}}=\mathrm{CH}-\mathrm{CH}=\mathrm{CH} \gamma_{\mathrm{n}} \stackrel{\text { fragmentation }}{\longrightarrow}-\mathrm{CH}=\mathrm{CH}-\mathrm{CH}=\stackrel{\mathrm{CH}}{\longrightarrow}+\underset{\substack{\mathrm{C} \\
\stackrel{\mathrm{P}}{\mathrm{C}}-\mathrm{CH}_{3} \mathrm{H}_{2}}}{\stackrel{\mathrm{C}}{\mathrm{C}}-}
\end{aligned}
$$

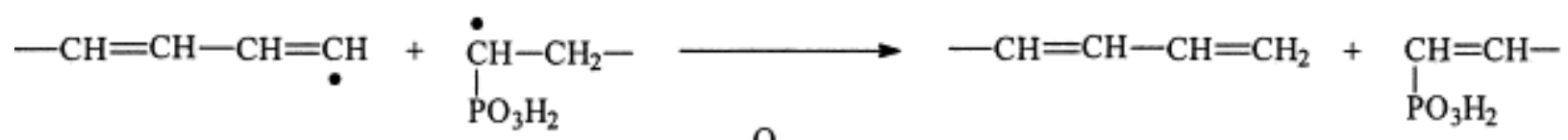

$$
\begin{aligned}
& \text { or } \\
& -\mathrm{CH}=\mathrm{CH}-\mathrm{CH}=\mathrm{CH} \underset{\bullet}{\stackrel{\mathrm{H}-\mathrm{P}(\mathrm{OH})_{2}}{\longrightarrow}} \underset{\text { reduction }}{\longrightarrow}-\mathrm{CH}=\mathrm{CH}-\mathrm{CH}=\mathrm{CH}_{2}+\cdot \mathrm{PO}_{3} \mathrm{H}_{2} \\
& -\mathrm{CH}=\mathrm{CH}-\mathrm{CH}=\mathrm{CH}_{2} \longrightarrow \mathrm{CH}_{2}=\mathrm{CH}-\mathrm{CH}=\mathrm{CH}_{2}
\end{aligned}
$$

Scheme. 6. 


\subsection{Degradation of poly(sodium 4-styrene sulfonate)}

\subsubsection{Thermogravimetric analysis}

The TGA curve for poly(sodium 4-styrenesulfonate) is shown in Fig. 12. There are four steps in the degradation. The first step occurs from 210 through $280^{\circ} \mathrm{C}$ and accounts for $5 \%$ mass loss. The second process is over the narrow temperature interval from 430 to $500^{\circ} \mathrm{C}$ and shows a mass loss of about 13\%. Degradation continues with further mass loss of $8 \%$ between 525 and $600^{\circ} \mathrm{C}$; this is followed by a slow degradation until the highest temperature used in this study, $900^{\circ} \mathrm{C}, 17 \%$ mass loss occurs in this region. At $900^{\circ} \mathrm{C}, 59 \%$ of the sample remains nonvolatile. The formation of foam was observed in these experiments; there is a volume expansion of 8 times at $400^{\circ} \mathrm{C}$.

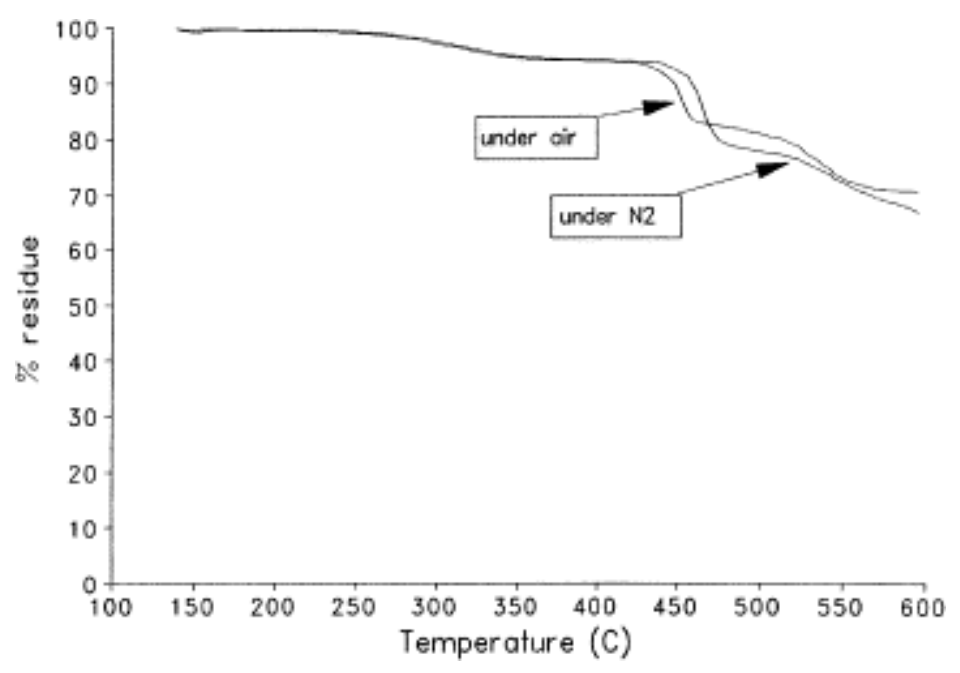

Fig. 12. Thermogravimetric analysis of poly(sodium 4-styrene sulfonate) under both nitrogen and air.

\subsubsection{Volatile products evolved during the degradation}

Water and $\mathrm{SO}_{2}$ evolve over the entire course of the degradation of the polymer while $\mathrm{COS}$ is only observed between 350 and $400^{\circ} \mathrm{C}$; over the temperature range where COS is observed there is no significant mass loss and there can only be a small amount of this material formed. Between 450 and $500^{\circ} \mathrm{C}$ methane and the products of polystyrene degradation $\underline{13}, \underline{14}, \underline{15}, \underline{16}, \underline{17}, \underline{18}$, benzene, styrene, toluene, and methylstyrene, evolve in addition to $\mathrm{H}_{2} \mathrm{O}$ and $\mathrm{SO}_{2}$. Between 550 and $580^{\circ} \mathrm{C}, \mathrm{CO}$ is first observed as well as an alcohol. The evolution profile is superimposed on the TGA curve in Fig. 13. 


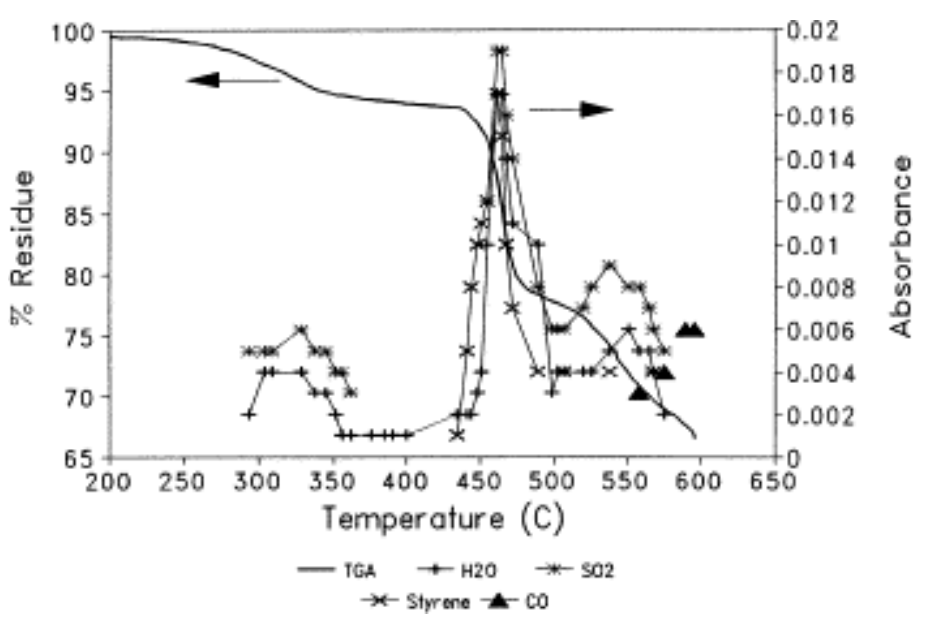

Fig. 13. Thermogravimetric analysis and evolved sulfur dioxide, styrene, carbon monoxide, and water from the thermal degradation of poly(sodium 4-styrenesulfonate) under nitrogen at $20^{\circ} \mathrm{C} / \mathrm{min}$.

\subsubsection{Analysis of residues}

The non-volatile residues from the degradation of poly(sodium 4-styrenesulfonate) under nitrogen were investigated by FTIR spectroscopy as a function of the temperature of degradation. The characteristic peaks due to the $-\mathrm{SO}_{3} \mathrm{Na}$ group at 1040 and $1180 \mathrm{~cm}^{-1}$ decrease upon heating and disappear by $550^{\circ} \mathrm{C}$. This indicates that not all of the $\mathrm{SO}_{3} \mathrm{Na}$ moieties are cleaved during the initial degradation step. A new strong band at $964 \mathrm{~cm}^{-1}$, absent in the original polymer, appears over the same temperature region and may be assigned to sulfite ion. The residue which was obtained by thermolysis below $350^{\circ} \mathrm{C}$ is immediately soluble in water, when the pyrolysis was conducted at 400 or $420^{\circ} \mathrm{C}$, the residue dissolved a little faster. When the pyrolysis was conducted at $490^{\circ} \mathrm{C}$ or above the residue was only partially soluble. At $800^{\circ} \mathrm{C}$ the major components of the residue is sulfite and sulfate ions.

The $\mathrm{C}-\mathrm{H}$ out-of-plane bend at $833 \mathrm{~cm}^{-1}$, observed in the spectrum of the polymer, shifts to 817 $\mathrm{cm}^{-1}$ at a temperature of $460^{\circ} \mathrm{C}$. Both of these positions are within the range for parasubstituted aromatic rings and do not match to any other substitution pattern[19]. This shift is taken to indicate that the substituent on the aromatic ring has changed; since the material is water soluble, there cannot be major changes in structure. Changes in the aromatic region in the proton NMR spectrum also show that some change has occured. One possible interpretation of this is the reduction of the sulfonic acid to a sulfinic acid. This reduction could involve the attack of an organic radical on the sulfonic acid group with the loss of an oxygen atom and the formation of an alkoxy radical. Hydrogen abstraction would lead to the formation of an alcohol which is an observed product. The infrared absorbances of the sulfinic acid appear in the same region as those of the sulfonic acid so no proof is available for the existence of the sulfinic acid so this must remain as speculation. Another new band appears in the infrared spectrum of the residue at $756 \mathrm{~cm}^{-1}$; this band is due to the $\mathrm{C}-\mathrm{H}$ out-of-plane bending mode and is characteristic of mono-substituted benzenes. This arises from the cleavage of the $\mathrm{C}-\mathrm{S}$ bond and subsequent hydrogen abstraction of a hydrogen atom by the phenyl radical to give styrene segments within the polymer chain. 
Elemental analysis of the residue obtained upon pyrolysis at $900^{\circ} \mathrm{C}$ indicates that it contains $10.43 \%$ sulfur. Unfortunately there was not enough residue to obtain an analysis for carbon as well but one can be sure that it does contain carbon since the sulfates and sulfites will not expand their volume and a volume expansion occurs upon degradation.

\subsubsection{Mechanism of the degradation}

The degradation proceeds by a very similar reaction pathway to that shown for sodium vinylsulfonate. The initial cleavage of the carbon-sulfur bond to give a styryl radical and $\mathrm{SO}_{3} \mathrm{Na}$ radical is depicted in Scheme. 7 . The sulfur radical will behave in the same fashion as for the vinylsulfonate. The styryl radical will hydrogen abstract and then degrade as polystyrene and as vinylsulfonate. Both styrene degradation products and an aromatic char are expected and observed.<smiles>CCC(C)CC(CC(C)C)c1ccc([S+]([O])([O-])O[Na])cc1</smiles>

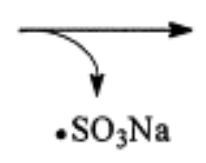<smiles>CCC(CC)CC(CC(C)[AlH2])c1ccccc1</smiles><smiles>CC(C)CC(CC(C)C[Mg])c1ccccc1</smiles><smiles>CC([AlH2])CC(CC([AlH2])C[13CH3])c1ccc([S+]([O])([O-])O[Na])cc1</smiles>

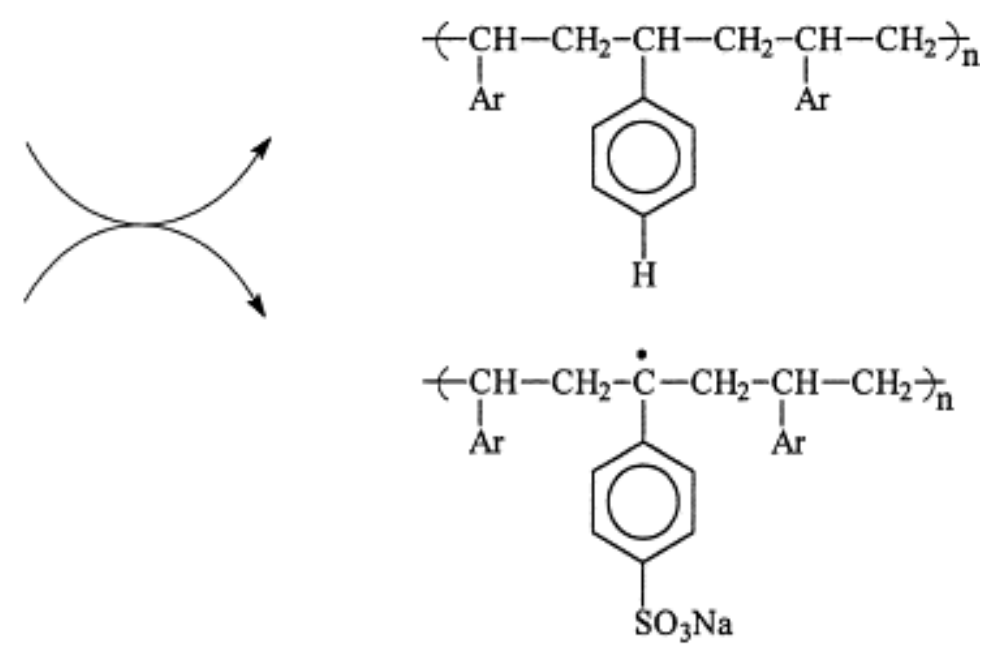

Scheme. 7.

\subsection{Poly(4-styrenesulfonic acid)}

\subsubsection{Thermogravimetric analysis}

The TGA curve for the thermal degradation of poly(4-styrenesulfonic acid) is shown in Fig. 14. The degradation occurs in a single step and the free acid is less stable than is the sodium salt. The mass loss is $35 \%$ at $400^{\circ} \mathrm{C}$ while the sodium salt has lost only $6 \%$ at $400^{\circ} \mathrm{C}$. At $600^{\circ} \mathrm{C}$ the 
free acid gives $54 \%$ non-volatile residue but, since the conversion to the acid is known to be incomplete, this also reflects the presence of some of the sodium salt.

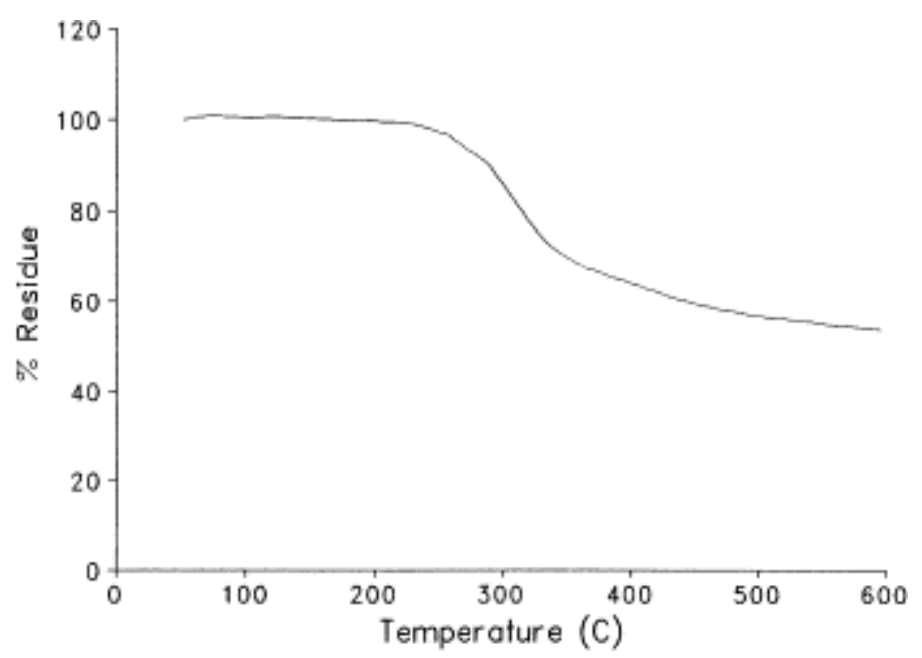

Fig. 14. Thermogravimetric analysis of poly(4-styrenesulfonic acid) at $20^{\circ} \mathrm{C}$ under nitrogen

\subsubsection{Volatile products evolved during the degradation}

The evolution of several of the gaseous products as a function of temperature is shown in Fig. 15. $\mathrm{SO}_{2}$ is the dominate product evolved between 190 and $530^{\circ} \mathrm{C}$, while water is also present during the entire degradation pathway but in relatively small amount. The same aromatic compounds, styrene, toluene, methylstyrene and benzene were also found amongst the gases.

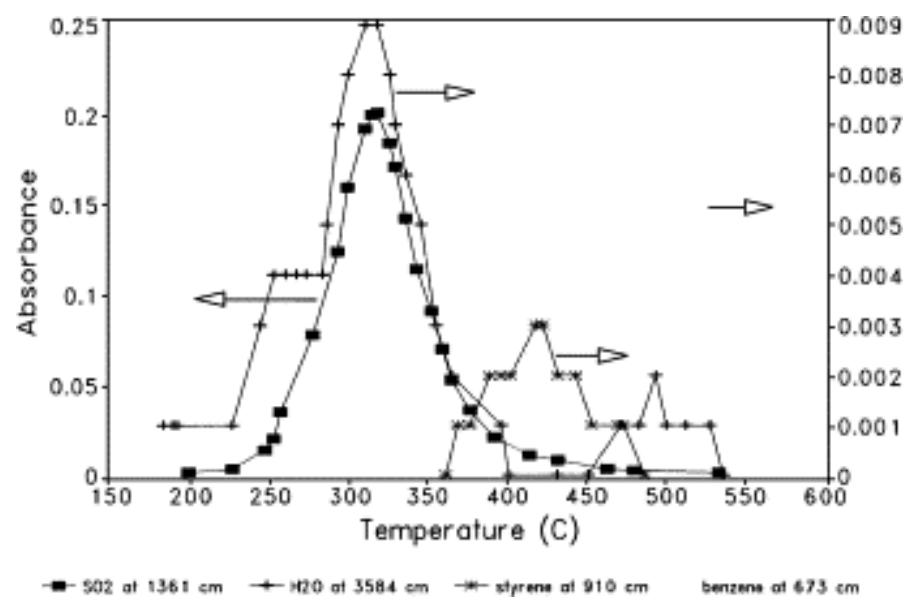

Fig. 15. Evolution of sulfur dioxide, water, styrene, and benzene from the thermal degradation of poly(4-styrenesulfonic acid) under nitrogen. 


\subsubsection{Mechanism of degradation}

The evolution of water occurs in the same temperature regime as $\mathrm{SO}_{2}$, between 185 and $400^{\circ} \mathrm{C}$, and this is likely due to the formation of sulfurous acid by the process noted above. Water is also evolved early in the degradation and this is likely due to the loss of physically combined water as has been observed for the other compounds. As noted for the sodium salt, loss of the sulfur substituent will lead to the formation of a styrene segment within the polymer after hydrogen abstraction occurs and this will lead to the observation of styrene degradation products.

\section{Conclusions}

TGA/FTIR combined with analysis of residues provides an excellent opportunity to understand the degradation pathway of the compounds in this study. The observation of foaming indicates that the char which is formed contains carbon as well as the inorganic salts which have been observed. The carbon is in a partially graphitized form. The salts produce a very large amount of char and they may prove useful to impart increased flame retardance to other polymers if they can be incorporated in a convenient manner into these polymers.

\section{Acknowledgements}

The kind cooperation of Dun Chen and Mattson Instruments in making their TGA/FTIR equipment available is gratefully acknowledged.

\section{References}

1 Suzuki M, Wilkie CA. J Polym Sci: Part A: Polym Chem 1995; 33:1025.

$\underline{2}$ Suzuki M, Wilkie CA. Polym Degrad Stab 1995;47:223.

3 Dong X, Geuskens G, Wilkie CA. Eur Polym 1995;31:1165.

4 Wilkie CA, Dong X, Suzuki M. Surface modification of polymers to achieve flame retardancy. In: Nelson G, editor. Fire and polymers 2, ACS Symposium Series \# 599. 1995 pp. 23644.

5 Wilkie CA, Suzuki M, Dong X, Deacon C, Chandrasiri JA, Xue TJ. Polym Degrad Stab 1996;54:117.

$\underline{6}$ Xue TJ, Wilkie CA. J Polym Sci: Part A: Polym Chem Ed 1997; 35:1275.

$\underline{7}$ Xue TJ, Wilkie CA. Polym Degrad Stab 1997;56:109.

$\underline{8}$ Pouchert CJ, editor. The Aldrich library of infrared spectra. 3rd ed. Milwaukee, WI: Aldrich Chemical Company, 1981.

9 Pierson RH, Fletcher AN, Clair Gantz ESt. Anal Chem 1956; 28:1218.

10 Nakamoto K. Infrared spectra of inorganic and coordination compounds. New York: John Wiley \& Sons, 1963. p. 107.

11 Nakamoto K. Infrared spectra of inorganic and coordination compounds. New York: John Wiley \& Sons, 1963. p. 87. 
12 Palmer HB, Cullis CF. The formation of carbon from gases. In: Waller Jr PL, editor. Chemistry and physics of carbon, vol. 1. New York: Marcel Dekker, 1965. p. 265 [chapter 5].

13 Chiantiore O, Camino G, Costa L, Grassie N. Polym Degrad Stab 1981;3:209.

14 Costa L, Camino G, Guyot A, Bert M, Chiotis A. Polym Degrad Stab 1982;4:245.

15 Guyot A. Polym Degrad Stab 1986;15:219.

16 McNeill IC, Zulfiqar M, Kousar T. Polym Degrad Stab 1990; 28:131.

17 Audiso G, Bertini F. J Anal Appl Pyrolysis 1992;24:61.

18 Suzuki M, Wilkie CA. Polm Degrad Stab 1995;47:217.

19 Conley RT. Infrared spectroscopy. 2nd ed. Boston (MA): Allyn and Bacon, 1972. p. 107-19. 